\title{
Individual Differences That Affect the Quality of Learning in Doctoral Candidates
}

\author{
Robert H. Cantwell, Jill J. Scevak, Sid Bourke, \& \\ Allyson Holbrook
}

\begin{abstract}
This chapter addresses issues relating to quality learning in the specific context of doctoral study. As the elite level of formal education, doctoral study places a high level of expectation on candidates to contribute in an important and original way to the field of study. This expectation imposes a high metacognitive load on students, in appropriately conceptualising the task, and in managing the intellectual, affective, and contingency demands that accompany its enactment. We suggest that the regulatory control behaviours of doctoral candidates may best be explained by reference to a broader conception of metacognitive knowledge than has traditionally been employed. We conclude that the sources of regulatory activity are multi-dimensional, and describe them in terms of an active multidimensional epistemic metacognitive framework that establishes the parameters of subsequent regulatory activity.

This chapter is about the capacity of $\mathrm{PhD}$ students to manage the metacognitive demands associated with the successful completion of the degree. The $\mathrm{PhD}$ has historically represented the highest level of tertiary study and, presumably, the highest quality of learning outcome. Although considerable variation exists in the structure of doctoral programs internationally, the intellectual outcome implied by the degree is common across all structures (Denicolo, 2003; Powell \& Green, 2003; Powell \& McCaulay, 2002). The context of the present chapter is the Australian PhD. The PhD in Australia is completed as a single research project, formally submitted as a thesis of 80,000-100,000 words. Assessment is by external examination of the thesis. There are not usually compulsory coursework components associated with the degree. The doctorate in Australia has experienced significant growth over the past decade. The Australian government, for example, reported a 4.1 per cent increase in $\mathrm{PhD}$ enrolments between 2008 and 2009 (DEEWR,
\end{abstract}


2010). Given the intellectual expectations associated with completion of a $\mathrm{PhD}$, the increasing numbers enrolling in the degree have given rise to issues of potential attrition and/or problems in candidature (Bourke, Holbrook, Lovat, \& Farley, 2004; Colebatch, 2002). With the broadening of the candidature base, there are possibilities of significant increase in the array of individual differences within the cohort. Such variation, we suggest, would affect the likelihood of problematic candidature and the potential for attrition from the degree.

Cantwell (2004) reported a comment by a university tutor that students who had entered her class via a mature-aged enabling programme seemed to 'get it', that they appeared to have some sense of what the intellectual demands of tertiary study were about, and of what they needed to do to meet those demands (Cantwell, Archer \& Bourke, 2001; Cantwell, 2007). The comment provides a useful introduction to the problem of quality learning in doctoral candidature. The notion of 'getting it' encapsulates a fundamental attribute of any successful educational experience, and particularly of the doctoral experience. Knowing what 'it' is that one should get, and knowing what the act of 'getting' requires appear to us to be central to understanding how the intellectual demands of doctoral candidature are perceived and managed, and through this, of understanding the underlying attributes of the individual candidate that enable the mastery of these demands to occur.

In this chapter, we consider some of the individual differences that potentially influence the quality of learning in doctoral students. Consistent with our thematic notion of 'getting it', we structure the chapter around two central issues: defining the quality of learning associated with doctoral study, and defining those within-candidate factors that we see as underlying the candidate's capacity to attain and maintain that level of quality in learning. We conclude the chapter with a discussion of an epistemic model of metacognition that postulates both a multi-layered nature of individual metacognitive knowledge, and the potential interplay of the cognitive and affective sub-domains in explaining metacognitive decision making among doctoral candidates.

\section{Defining the 'It': Assumptions of Quality in the Doctoral Task}

It would not be a major revelation for most doctoral candidates and their advisors/supervisors to be told that doctoral study is, by its nature, both difficult and effortful, and that it remains so for an extended period of time. What is more problematic, however, is the question of what that difficulty actually is, and therefore of what the presumed required effort is directed towards. 
Understanding the doctorate as an issue of quality of educational outcome, then, requires consideration of two questions: what are the intellectual expectations associated with doctoral candidature, and where do we draw the line in the developmental sand that delineates when the point of being 'doctoral' has been reached?

There is consensus that the key to understanding the nature of the intellectual demands of doctoral study lies in the centrality of the notion of 'contribution' (Denicolo, 2003; Holbrook, Bourke, Dally \& Lovat, 2004; Powell \& Macaulay, 2002), although there remains, as Powell and Green (2003) noted, ambiguity in what the underlying attributes of 'original contribution' might actually be. Holbrook et al. (2004) conducted a cross-institutional and crossdisciplinary study of $\mathrm{PhD}$ examiners' reports. $\mathrm{PhD}$ examination in Australia involves a critical evaluation of the thesis by two or three specialists in the field, who are external to the candidate's institution. Their reports provide evidence for the particular university to consider to determine the acceptance or otherwise of the thesis for the degree. One of the major findings of the Holbrook et al. (2004) study was the emphasis given by the examiners to the quality of contribution evident in the thesis. By this was meant a quite broad definition of contribution, one which was marked by an acknowledgement that the candidate displayed the hallmarks of an independent researcher. Examiners were sensitive to the capacity of the candidate both to ask a significant and original question of the field and to respond to that question in a methodologically appropriate (and sometimes innovative) way. In an ongoing study of doctoral examination, Holbrook and Bourke (2010; Bourke \& Holbrook, 2010) asked examiners to rate the importance of twelve indicators of quality in their thinking about thesis quality. Ratings were given to quality indicators for both Master's by research and $\mathrm{PhD}$ theses. Preliminary results are summarised in Table 5.1. Examination of these data suggests a difference in expectations associated with the two degrees. The emphasis in examination of the Master's degree appears to lie (relative to the $\mathrm{PhD}$ ) in the indication of competence rather than substantive and/or methodological innovation. From the standpoint of defining the expectations surrounding the $\mathrm{PhD}$, the Master's degree can be seen as representing a relatively closed system indicating a 'mastery' of the field, where the $\mathrm{PhD}$ may be characterised as an open system indicating a shift beyond the given of the field. As such, to a level beyond that of the Master's degree, the $\mathrm{PhD}$ embodies the expectation of a significant intellectual leap, one that moves from engagement with the theoretical to engagement with the hypothetical.

If the expectations associated with doctoral study are concerned primarily with making a significant contribution to the field, either substantively or 
TABLE 5.1. Examiner Ratings of Quality Indicators in Research Master's and PhD Examination (Holbrook \& Bourke, 2010)

\begin{tabular}{|c|c|c|}
\hline Quality Indicator & $\begin{array}{l}\text { Importance in } \\
\mathrm{PhD} \text { examination }\end{array}$ & $\begin{array}{l}\text { Importance in Research } \\
\text { Master's examination }\end{array}$ \\
\hline $\begin{array}{l}\text { CONTRIBUTION: Substantial to } \\
\text { the discipline/field }\end{array}$ & 1 & 9 \\
\hline $\begin{array}{l}\text { CONTRIBUTION: Advance in } \\
\text { knowledge/theory/techniques }\end{array}$ & 2 & 3 \\
\hline $\begin{array}{l}\text { LITERATURE: Use/application } \\
\text { throughout the thesis }\end{array}$ & 3 & 6 \\
\hline $\begin{array}{l}\text { CONTRIBUTION: Originality } \\
\text { within the discipline/field }\end{array}$ & 4 & 5 \\
\hline $\begin{array}{l}\text { ANALYSES/RESULTS: Effective } \\
\text { application of analyses }\end{array}$ & 5 & 4 \\
\hline $\begin{array}{l}\text { ANALYSES/RESULTS: } \\
\text { Appropriateness of analyses }\end{array}$ & 6 & 2 \\
\hline $\begin{array}{l}\text { APPROACH/METHOD: Effective } \\
\text { application of methods }\end{array}$ & 7 & 12 \\
\hline $\begin{array}{l}\text { LITERATURE: Accuracy of } \\
\text { interpretation }\end{array}$ & 8 & 10 \\
\hline $\begin{array}{l}\text { APPROACH/METHOD: Soundness } \\
\text { of approach adopted }\end{array}$ & 9 & 7 \\
\hline $\begin{array}{l}\text { LITERATURE: Completeness of } \\
\text { relevant coverage }\end{array}$ & 10 & 1 \\
\hline $\begin{array}{l}\text { PRESENTATION: Clear and } \\
\text { coherent presentation of study }\end{array}$ & 11 & 8 \\
\hline $\begin{array}{l}\text { PRESENTATION: Correct grammar } \\
\text { and expression throughout }\end{array}$ & 12 & 11 \\
\hline
\end{tabular}

methodologically, the question remains as to what developmental changes in the quality of thinking underpin the capacity to generate an original contribution. Hypothetical reasoning as the basis of contribution implies a capacity to reason about the field rather than, as would be the expectation of the master's degree, reasoning within the field. It is marked by a transition, substantively and potentially methodologically, from the known to the unknown, and represents for the candidate a developmental imperative towards significant epistemological and ontological change. Such insights are not new and have been spoken about in the literature relating to the doctorate since the 1970 and 1980s. At the centre of these discussions has been the recognition of intellectual uncertainty as the defining characteristic of doctoral study. Basseches (1984) gave emphasis to the role of new problem solving in doctoral study (i.e. contribution), suggesting that this requires a doctoral 
student to operate in a context of uncertainty, with its accompanying contradictions and ambiguities, and use this as a basis for thought. In a similar vein, Kramer (1989) spoke of the need for doctoral students to engage in new ways of thinking reflective of an increasingly sophisticated epistemological awareness. The characteristics of these new ways of thinking involve, at least at the higher conceptual level, an awareness and understanding of the relativist, non-absolutist nature of knowledge, an acceptance of contradiction as part of reality, and the integration of contradiction in an all-encompassing system (Kramer 1989). Biggs and Collis (1989) equally saw the transition into higher-level postgraduate study and research as requiring fundamental shifts in the modality of thinking:

When one questions the conventional bounds of theory and practice and establishes new ones, one enters the Formal-2. Formal-2 thought may thus be seen in high level innovations in many fields; it is institutionalised in postgraduate study and in basic research. If principles relate to other principles to form disciplines, questioning and reshaping those disciplines is to operate at a more abstract level than Formal-1 itself. (p. 157)

In short, the doctorate as a task is replete with intellectual uncertainty - in the openness of the substantive concerns in generating a contribution to the field (in Shaw's words, 'to extend the forefront of the discipline' - see Powell \& Macaulay, 2002), and in the capacity of the individual candidate not only to recognise the need for and existence of such uncertainty, but to possess those metacognitive attributes central to its management.

If the notion of uncertainty pervades both the substantive and methodological concerns of the thesis, it is also reasonable to suggest that uncertainty will pervade the individual's relationship to that context. How the candidate engages with the doctoral task is as much an issue of the management of the individual's affective or emotional response to uncertainty as it is of the management of the response to intellectual uncertainty. The fusion of the affective and the intellectual within doctoral study has been emphasised by Mezirow (1991) through the notion of perspective transformation. Tennant and Pogson (1995) describe this process as follows: 'The self, in effect, stands in a dialectical relationship to experience, both forming and being formed by the experience it encounters' (p. 169). In other words, there is a fundamental ontological change accompanying the doctoral experience reflective of both the epistemological assumptions of contribution and the personal, social, and cultural transformations associated with its development (Tennant, 2000).

The process of becoming doctoral, of achieving the requisite quality of learning, is a complex metacognitive process embodying not only traditional 
self-regulatory actions, but the embedding of these actions within a broader metacognitive framework that includes management of higher intellectual and affective states. Individual variation in the management of the intellectual and affective demands associated with doctoral study necessarily requires examination of those attributes of the individual's beliefs and dispositions that inform self-regulatory choices normally associated with quality learning outcomes. The transformative processes associated with doctoral study, and with the generation of contribution, are underpinned by the increasing sophistication of beliefs about knowledge and about self-as-knower (both descriptively and evaluatively). We suggest, in the final part of this chapter, that these beliefs and dispositions represent an epistemic level of metacognitive functioning.

\section{Defining the 'Getting': What Are the Attributes of PhD Candidates Associated with Quality Learning in Doctoral Candidature}

Engagement with PhD study involves an extended period of intellectual commitment to a task that is typically ill-defined, ill-structured, and replete with uncertainty. It is a task, therefore, that inherently involves the management of risk. The intellectual bar associated with successful doctoral candidature is high, representing a capacity to hypothesise about the givens of the field, and a capacity to rigorously test such hypothesising in a discipline-appropriate way. In short, doctoral candidature involves a high degree of metacognitive prowess if the potential intellectual and emotional challenges of candidature are to be met. It is this that provides a potentially significant source of individual variation in candidature. Many of the metacognitive factors that have been shown to influence learning at other levels of education are likely to also come into play in the doctoral context. Tacit assumptions (held by both supervisors and students) of expertise as a learner may well hold in relation to the more basic competencies developed in pre-doctoral study (Scevak, Budd \& Cantwell, 2010). However, the acknowledgement of the enhanced intellectual challenges (and therefore emotional challenges) within the doctoral task also suggests that how the learning process is managed in doctoral study will continue to impose a significant metacognitive load.

In a study of the metacognitive attributes of doctoral candidates, Cantwell and colleagues (Scevak, Cantwell, Bourke \& Reid, 2007; Cantwell, Scevak, Bourke \& Holbrook, 2012) hypothesised the existence of a superordinate level of metacognitive awareness that would provide a source of individual variation in how doctoral students respond to the potential intellectual and affective challenges of doctoral study. We reasoned that 'problematic candidature' 
is more likely to be situated in the broader metacognitive beliefs driving decision making than in the more specific skill level typically underpinning problematic learning at lower levels of education. In this we were guided by Cantwell's (2004, 2010; Cantwell et al., 2012; see also Vermunt, 1998, Vermunt \& Vermetten, 2004, ten Cate, Snell, Mann \& Vermunt, 2004) account of the interactions between affective and metacognitive elements in learning. We suggested that the specific regulatory actions initiated by individuals as learning progresses are informed by higher-order representations of knowledge, knowing, and self-as-knower that provide the parameters through which self-regulatory decisions are generated.

Cantwell et al. (2012) hypothesised that an examination of higher-order dispositional metacognition and affect among doctoral candidates would provide evidence of individual variation in response to the complexities and demands of doctoral study. We reasoned that the responses of candidates to the demands of doctoral study would relate to four potential sources of challenge: those to do with Coping (the capacity to cope with the contingencies and demands of complex lives and study); those to do with Persisting (the capacity to persist and reinvigorate themselves in times of challenge); those to do with Engaging (the willingness to engage in difficult, complex, and abstract mental effort over an extended time frame); and those to do with Capacity (the presence of the academic wherewithal to achieve this). We further reasoned that how these responses played out would be reflective of an interaction among the three metacognitive domains that underlie the internal domains in learning described by Cantwell (2004) (see Figure 5.1). These are:

a) intellectual factors associated with higher-order beliefs and theories about knowledge, regulation, and intellectual uncertainty;

b) affective factors associated with higher-order beliefs and theories about self-as-learner, including both the sense of efficacy as a doctoral student and the capacity to manage the affective challenges to that sense of efficacy as candidacy progresses; and

c) contingency response factors associated with higher-order beliefs and theories about how best to respond to and manage the challenges faced in candidature, including the acceptance or abrogation of responsibility, the quality of volitional choices, and the disposition towards procrastination.

Based on this reasoning, Cantwell et al. (2012) surveyed 263 doctoral students (across all stages of candidature) to explore three questions: (1) Do doctoral candidates present with a metacognitive profile consistent with expectations of an elite cohort of students? (2) Is there evidence of individual variation within this profile? (3) What are the underlying dimensions of the metacognitive beliefs of doctoral candidates? The majority of the students were 


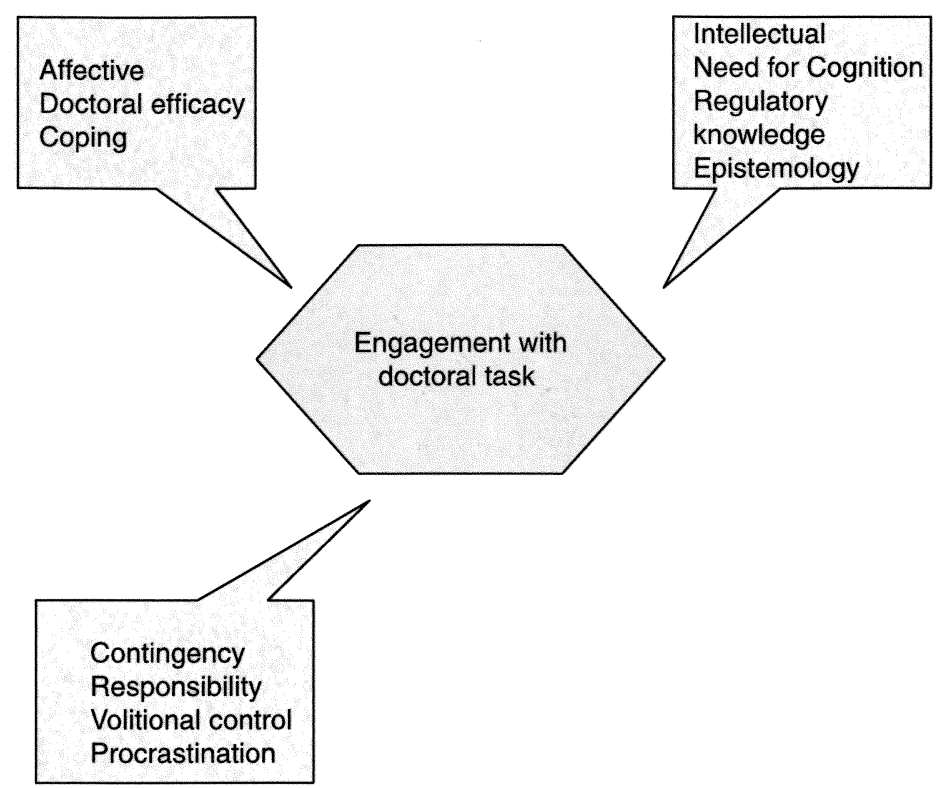

FIGURE 5.1. Within-candidate factors hypothesised to influence the quality of doctoral engagement.

female and full time, but the sample was spread across disciplines and age levels. Instrumentation consisted of eight questionnaires selected as representative of the three metacognitive domains of affect, disposition, and contingency response:

a) Affective measures included the Reactions to Daily Events questionnaire (Greenglass et al., 1999). This instrument reports on different aspects of coping with challenging tasks and contexts including Proactive Coping, Reflective Coping, Preventative Coping, Emotional \& Instrumental Support Seeking, and Avoidance. A measure of Doctoral Efficacy was also constructed (Scevak et al., 2007).

b) Intellectual measures included Need for Cognition (Cacciopo, Petty \& Kao, 1984), a measure of the attractiveness of complex learning to individuals; Epistemological Beliefs (Schommer, 1993), a measure of beliefs about the structure of knowledge and means of acquiring knowledge; and Metacognitive Awareness (Schraw \& Denison, 1994), a measure of the individual's knowledge of cognition and regulation of cognition.

c) Contingency response measures included Academic Volitional Control (McCann \& Garcia, 1999), a measure of preference for the volitional strategies of Stress Reduction, Use of Negative Incentives and Self Enhancing Strategies; Doctoral Responsibility (Kleuver \& Green, 1998) as a measure 
of acceptance (indicated by a low score) or abrogation (indicated by a high score) of responsibility (actual and preferred) both early and late in candidature; and Procrastination (Muszynski \& Akamatsu, 1991), a measure of tendency to procrastinate based on Feelings of Inadequacy, Response to Pressure, and Pragmatic Reduction of Candidature goals.

Each scale was subjected to single-factor congeneric analysis using Amos v17 (Arbuckle 2008) to allow for parsimonious forms of each instrument to be generated. Sample items for each of the scales utilised in the study are included in Table 5.2.

The analysis supported the proposition that doctoral candidates present at the group level with a relatively sophisticated profile in relation to the three domains of measurement (see Figure 5.2). The cohort overall endorsed those affective measures indicating a capacity to constructively control affective states (doctoral efficacy, proactive coping, reflective coping, preventative coping, and emotional and instrumental support seeking); those dispositional measures indicating a capacity to engage with complex, high-level learning (need for cognition, knowledge and regulation of cognition, structure of knowledge, and acquisition of knowledge); and those contingency response measures indicating a capacity to manage periodic challenges to learning (internalising responsibility for the doctorate and the use of self-enhancing volitional strategies). The cohort was also less likely to endorse those contingency response measures indicating less constructive management of challenges to learning (simple stress reduction and use of negative incentives, all procrastination measures).

The second question addressed in the Cantwell et al. (2012) study concerned the possibility that, despite the relative sophistication of the group profile, significant within-cohort individual differences may be present. Two sources of variation could have been present: one in the capacity to manage the higherorder intellectual demands associated with generating a 'contribution', and the other in the management of the affective demands associated with those higher-level uncertainties. The more basic procedural demands of the doctoral task (the conventional self-regulatory dimension) would not normally be expected to be a source of individual differences at this level. A two-step cluster analysis (PASW Statistics, 2009) using standardised scale scores revealed two clear clusters of students, representing 62 per cent and 38 per cent of the cohort, respectively. The cluster groups differed significantly on all measures with the exception of the use of stress reduction as a volitional strategy (see Figure 5.3). These variations were evident across each of the three domains of measurement: in the management of affect associated with doctoral study; 
TABLE 5.2. Sample Scale Items from Instruments Used by Cantwell et al. (2012)

\begin{tabular}{|c|c|c|}
\hline $\begin{array}{l}\text { Internal } \\
\text { Factors }\end{array}$ & Scale & Sample Items \\
\hline \multirow[t]{6}{*}{$\begin{array}{l}\text { Affective } \\
\text { Factors }\end{array}$} & $\begin{array}{l}\text { Reactions to Daily Events } \\
\text { (Greenglass et al. 1999) }\end{array}$ & \\
\hline & Proactive Coping & $\begin{array}{l}\text { I always try to find a way to work } \\
\text { around obstacles; nothing really stops } \\
\text { me. }\end{array}$ \\
\hline & Reflective Coping & $\begin{array}{l}\text { In my mind I go through many } \\
\text { different scenarios in order to prepare } \\
\text { myself for different outcomes. }\end{array}$ \\
\hline & Preventative Coping & I plan for future eventualities. \\
\hline & Support Seeking & $\begin{array}{l}\text { Information I get from others } \\
\text { has often helped me deal with my } \\
\text { problems. }\end{array}$ \\
\hline & $\begin{array}{l}\text { Doctoral Efficacy (Cantwell } \\
\text { et al., 2012) }\end{array}$ & $\begin{array}{l}\text { As a doctoral student, I am (or expect } \\
\text { to be) able to locate and understand } \\
\text { relevant literature }\end{array}$ \\
\hline \multirow[t]{7}{*}{$\begin{array}{l}\text { Dispositional } \\
\text { Factors }\end{array}$} & $\begin{array}{l}\text { Metacognitive Awareness } \\
\text { (Schraw \& Denison, 1994) }\end{array}$ & \\
\hline & Knowledge of Cognition & $\begin{array}{l}\text { I use my intellectual strengths to } \\
\text { compensate for my weaknesses. }\end{array}$ \\
\hline & Regulation of Cognition & $\begin{array}{l}\text { I ask myself if I have considered all } \\
\text { options after I solve a problem. }\end{array}$ \\
\hline & $\begin{array}{l}\text { Epistemological Awareness } \\
\text { (Schommer, 1993) }\end{array}$ & \\
\hline & Structure of Knowledge & $\begin{array}{l}\text { It's a waste of time to work on } \\
\text { problems which have no possibility } \\
\text { of coming out with a clear-cut and } \\
\text { unambiguous answer. (Item reverse } \\
\text { scored for positive valence.) }\end{array}$ \\
\hline & Acquisition of Knowledge & $\begin{array}{l}\text { Students have a lot of control over } \\
\text { how much they can get out of an } \\
\text { article. }\end{array}$ \\
\hline & $\begin{array}{l}\text { Need for Cognition } \\
\text { (Cacciopo, Petty \& Kao, } \\
\text { 1994) }\end{array}$ & $\begin{array}{l}\text { I prefer just to let things happen } \\
\text { rather than try to understand why } \\
\text { they turned out that way. (Item } \\
\text { reverse scored for positive valence.) }\end{array}$ \\
\hline
\end{tabular}




\begin{tabular}{|c|c|c|}
\hline $\begin{array}{l}\text { Internal } \\
\text { Factors }\end{array}$ & Scale & Sample Items \\
\hline \multirow{11}{*}{$\begin{array}{l}\text { Contingency } \\
\text { Response } \\
\text { Factors }\end{array}$} & $\begin{array}{l}\text { Academic Volitional Strategies } \\
\text { (McCann \& Garcia, 1999) }\end{array}$ & \\
\hline & Stress Reduction Strategies & $\begin{array}{l}\text { I usually meditate or use some form } \\
\text { of relaxation techniques so I am } \\
\text { better able to concentrate on my } \\
\text { thesis work. }\end{array}$ \\
\hline & Use of Negative Incentives & $\begin{array}{l}\text { I think about the possible negative } \\
\text { consequences of doing poorly in my } \\
\text { doctoral study. }\end{array}$ \\
\hline & Self-Enhancing Strategies & $\begin{array}{l}\text { I remind myself that I usually do fine } \\
\text { on tasks when I stay on track with my } \\
\text { work. }\end{array}$ \\
\hline & $\begin{array}{l}\text { Doctoral Responsibility } \\
\text { (Kleuver \& Green, 1998) }\end{array}$ & \\
\hline & $\begin{array}{l}\text { Ideal Early Candidature } \\
\text { Perceived Early Candidature }\end{array}$ & $\begin{array}{l}\text { Responsibility for progressing } \\
\text { through the thesis rests with (student } \\
\text {.. university) (IS ... SHOULD). } \\
\text { (A higher score indicates the placing } \\
\text { of responsibility for progress with the } \\
\text { university.) }\end{array}$ \\
\hline & $\begin{array}{l}\text { Ideal Late Candidature } \\
\text { Perceived Late Candidature }\end{array}$ & $\begin{array}{l}\text { Responsibility for scheduling the } \\
\text { pace and time line for completion } \\
\text { of the thesis rests with (student... } \\
\text { university) (IS ... SHOULD). } \\
\text { (A higher score indicates the placing } \\
\text { of responsibility for progress with the } \\
\text { university.) }\end{array}$ \\
\hline & $\begin{array}{l}\text { Procrastination } \\
\text { (Muszynski \& Akamatsu, } \\
\text { 1991) }\end{array}$ & \\
\hline & Feelings of Inadequacy & $\begin{array}{l}\text { When a problem comes up with } \\
\text { my thesis, I tend to get anxious and } \\
\text { worried about whether I will be able } \\
\text { to handle it. }\end{array}$ \\
\hline & Response to Pressure & $\begin{array}{l}\text { If I was required to complete my } \\
\text { thesis in a specified reasonable } \\
\text { amount of time, I could do it more } \\
\text { quickly. }\end{array}$ \\
\hline & Pragmatic Goal Reduction & $\begin{array}{l}\text { I have worked on the thesis for so } \\
\text { long that I have lost all desire to do it. }\end{array}$ \\
\hline
\end{tabular}




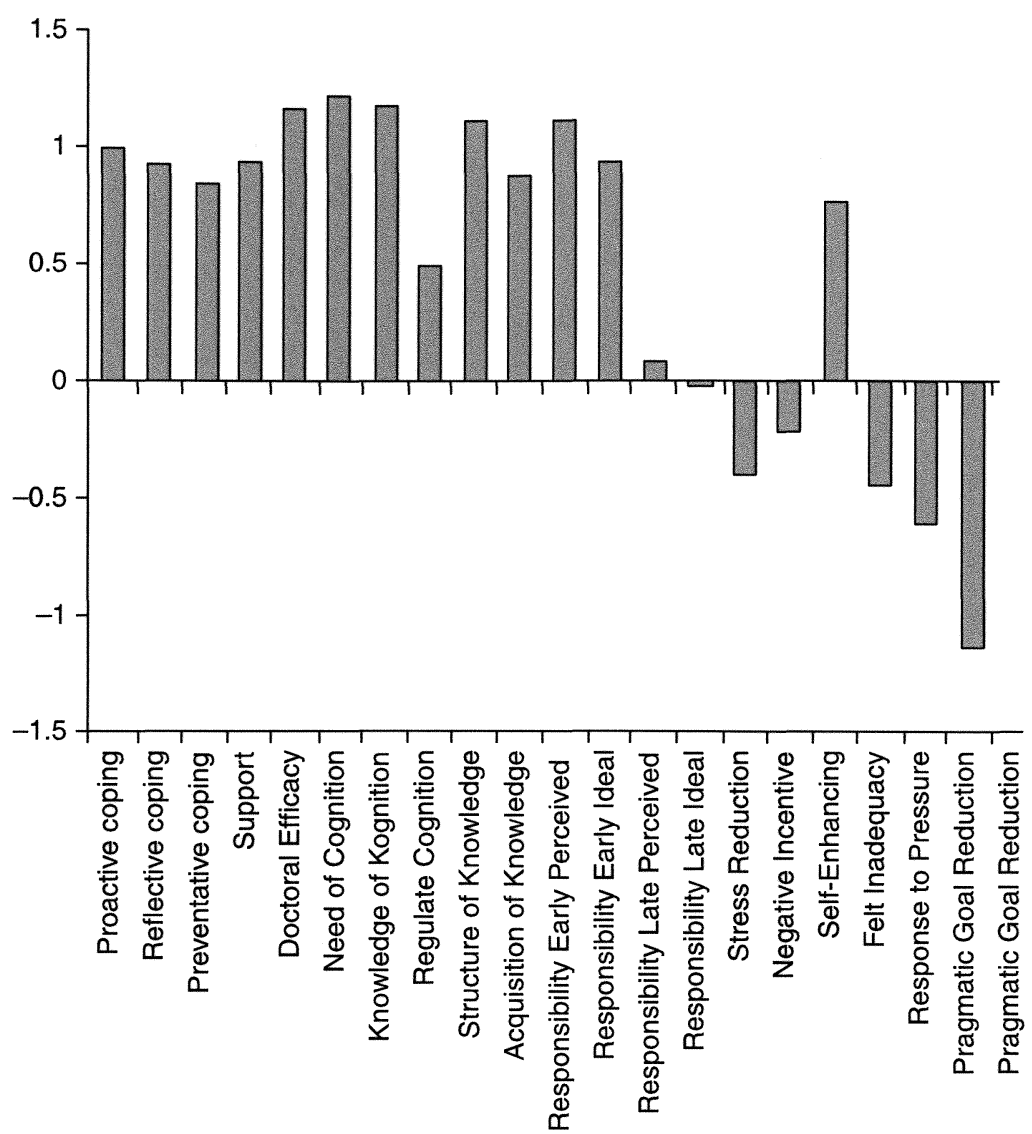

FIGURE 5.2. Deviations from scale midpoints for whole cohort (all scales converted to 5-point metric).

in both the awareness of and management of the intellectual demands associated with doctoral study; and in the management of contingency and in the task appropriateness of response to contingency. The cluster solution revealed a substantial group of students ( 38 per cent) who, while still coming from a relatively high baseline, scored lower on all of the 'constructive' measures indicated earlier, and scored higher on all of the less constructive measures indicated earlier when compared to the majority cluster. We interpreted this as potentially indicating a lesser likelihood of generating appropriate metacognitive responses to the demands of doctoral candidature, and through this a potentially greater likelihood of experiencing problems in candidature. We concluded from this analysis that any assumptions of metacognitive homogeneity within the doctoral cohort could not be supported. 


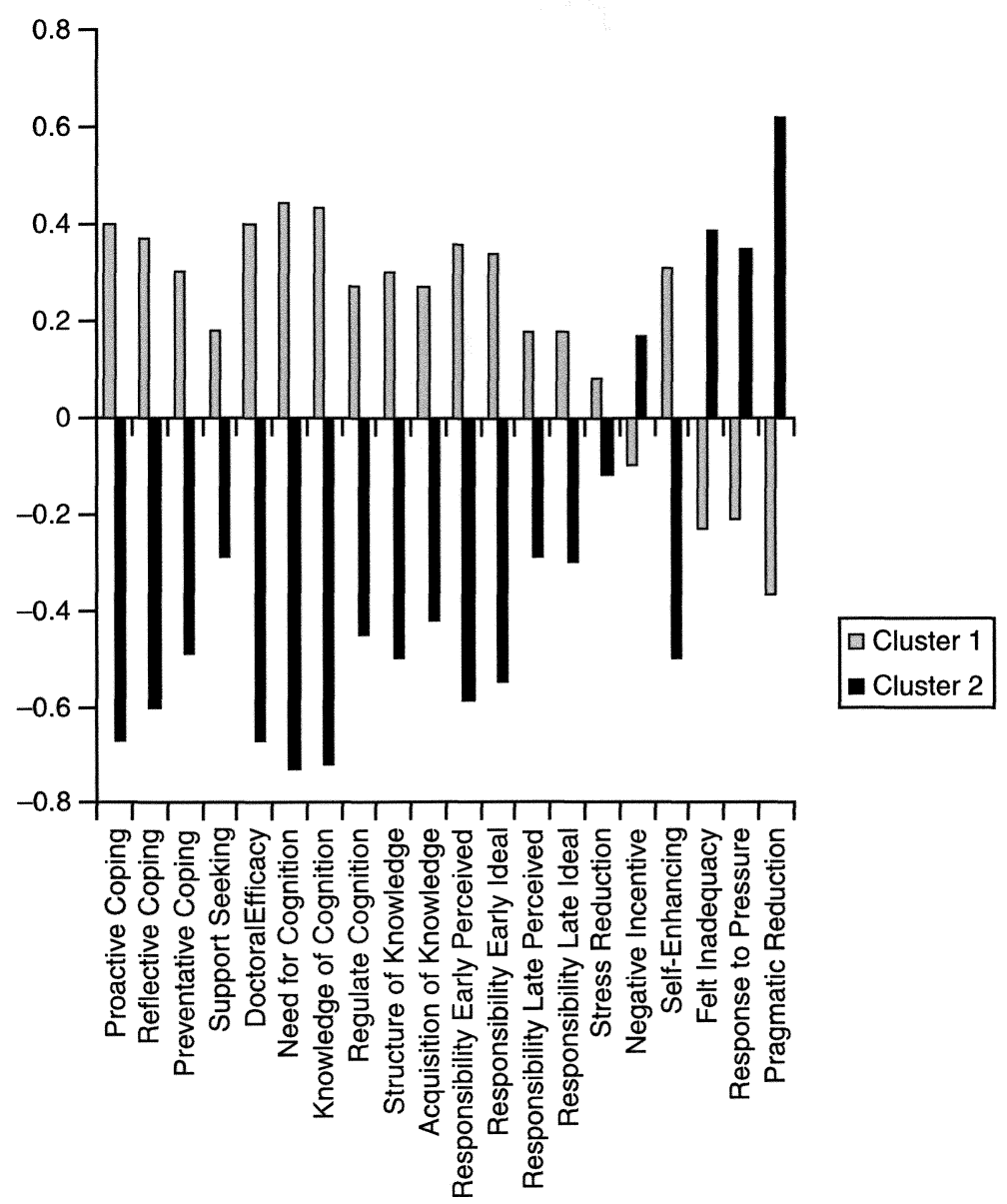

FIGURE 5.3. Mean scale scores for cluster groupings (standardised data).

The third question addressed in the Cantwell et al. (2012) study concerned the underlying dimensionality of the metacognitive beliefs held by the doctoral students. Using Principal Component Analysis with Varimax rotation (PASW Statistics, 2009), three factors were identified (see Table 5.3), all of which discriminated between cluster groups. The first factor (labelled 'Coping') implied the presence of both the affective and intellectual wherewithal necessary to manage the demands of doctoral study - coping, efficacy, as well as underlying regulatory competencies. The second factor (labelled 'Naivety'), on the other hand, indicated the impact of a naive understanding of the intellectual and self-regulatory properties of effective candidature, and the flow-on of this to diminished efficacy, less constructive volitional choices, and procrastination. 
TABLE 5.3. Factor Loadings for Principal Component Analysis of All Twenty Metacognitive Scales

\begin{tabular}{lccc}
\hline Metacognitive Scale & \multicolumn{3}{c}{ Component } \\
\cline { 2 - 4 } & Coping & Naivety & Disengagement \\
\hline Self-Enhancing Strategies & .801 & .068 & -.040 \\
Proactive Coping & .721 & -.270 & .063 \\
Reflective Coping & .706 & -.055 & -.026 \\
Preventative Coping & .684 & -.114 & .087 \\
Regulation of Cognition & .664 & .068 & .001 \\
Knowledge of Cognition & .629 & -.384 & -.195 \\
Stress Reducing Behaviours & .529 & .368 & .021 \\
Acquisition of Knowledge & .372 & -.150 & -.145 \\
Support-Seeking Behaviours & .359 & .072 & -.063 \\
Use of Negative Incentives & .203 & .708 & -.143 \\
Procrastination: Felt Inadequacy & -.165 & .707 & -.151 \\
Need for Cognition & .173 & -.648 & -.309 \\
Procrastination: Goal Reduction & -.294 & .576 & .170 \\
Procrastination: Response to Pressure & -.061 & .560 & .039 \\
Structure of Knowledge & -.120 & -.495 & -.306 \\
Doctoral Efficacy & .420 & -.470 & -.199 \\
Responsibility Early - Perceived & -.034 & .223 & .802 \\
Responsibility Early - Ideal & -.053 & .272 & .757 \\
Responsibility Late - Perceived & -.103 & -.231 & .697 \\
Responsibility Late - Ideal & -.010 & .020 & .669 \\
\% Variance accounted for & 19.52 & 15.60 & 12.65 \\
Cronbach alpha & .81 & .74 & .70 \\
\hline
\end{tabular}

Note: Extraction Method: Principal Component Analysis. Rotation Method: Varimax with Kaiser Normalization. Loadings $>.30$ in bold.

The third factor (labelled 'Disengagement') was similarly marked by a diminished understanding of the intellectual demands of doctoral study combined with an abrogation of personal responsibility for doctoral progress. Cantwell et al. (2012) further found significant differences between clusters in relation to the three factors: Cluster 1 were significantly higher scoring on the Coping factor than Cluster 2, and significantly lower scoring on the Naivety and Disengagement factors than Cluster 2.

Overall, there were three broad findings:

a) the results supported the notion of non-homogeneity in doctoral candidature despite its status as the pinnacle of formal study;

b) although significant variation was found in relation to the core intellectual demands of doctoral study, this variation was compounded by further variation in the quality of affective disposition brought to the task, and the quality of response to contingency management demands; 
c) these variations were reflected in the underlying dimensionality of the doctoral students' metacognitive beliefs, which may indicate powerful (and possibly resilient) frames of reference governing the metacognitive decision making in candidature.

\section{Epistemic Metacognition and Quality Learning}

The chapter began with a discussion of the notion of 'getting it' as a metaphor for the process of engaging with the higher-order intellectual demands of doctoral study. The metaphor implied two relevant questions for an account of the quality learning in doctoral study. First, the concept of 'it' was discussed in terms of the inherent complexity and abstractness of the doctoral task itself. The notion of 'contribution' was seen as both the primary goal and indicator of doctoral quality (Holbrook \& Bourke, 2010), and was described in terms of 'extending the forefront of the discipline', reflecting a capacity to hypothesise about and rigorously test an issue beyond the givens of the field. Generating a contribution is marked by both complexity and high levels of abstraction, reflected in Biggs and Collis's (1989) description of the Formal-2 mode as the underlying modality of postgraduate and research thinking. 'It' is a nontrivial, difficult task requiring completion over an extended time period. The second aspect of 'getting it' addressed earlier was the notion of 'getting': what are the underlying attributes of the individual candidate that allow for such a complex, abstract, and difficult task to be meaningfully engaged in and mastered over such an extended time frame? In the discussion of this aspect we reported on a study of doctoral metacognition (Cantwell et al., 2012) in which we profiled doctoral candidates in relation to three key metacognitive attributes: those attributes underlying management of the intellectual demands of the doctoral task, those attributes underlying management of the affective demands of the doctoral task, and those attributes underlying management of contingency in the doctoral task. In analysing participant responses, the cohort was grouped in terms of stronger and weaker representations of the constituent elements of metacognitive management, based on more effective and less effective constellations of metacognitive beliefs that drive regulatory decision making. There was also a significant relationship between cohort grouping and endorsement of the underlying dimensions of Coping, Naivety, and Disengagement.

In the remainder of this chapter, we address the implications of the results of both the Holbrook studies (Holbrook et al., 2004; Holbrook \& Bourke, 2010; Bourke \& Holbrook, 2010) and the Cantwell et al. (2012) study for an account of the nature of metacognitive knowledge in doctoral students and its relationships to quality learning. 
Traditionally, metacognitive research has focused on self-regulatory capacities and their relationships to planning, monitoring, and evaluative behaviours. More recently, research has begun to extend the remit of metacognition in learning to acknowledge the relationships between regulatory decision making and other, perhaps more general, domains of individual differences. Veenman, Van Hout-Wolters, and Afflerbach (2006) gave impetus to this process by identifying the need to examine metacognition in the context of other individual differences, although they did not extend this to suggest a more general unified metacognitive construct. Nonetheless, there has been some movement in extending the scope of explanation of effective metacognitive activity. A recent special issue of the journal Metacognition and Learning (April 2010), for example, considered the relationships between epistemology and metacognition. For many of the contributors, the link between epistemic beliefs and metacognitive behaviours was emphasised, giving rise to at least some degree of recognition of the potential mutuality between epistemological and metacognitive beliefs (see Bromme, Pieschl \& Stahl, 2010; Mason et al., 2010; Muis \& Franco, 2010; Richter \& Schmid, 2010).

Aspects of the outcomes of the Cantwell et al. (2012) study are consistent with a multi-dimensional account of metacognitive activity. Although the focus in the Metacognition and Learning articles was on the relationships between epistemology and metacognition (a relationship empirically evident in the Cantwell et al. data), we consider the possibility of interactions between multiple sources of individual differences, including epistemology, and metacognitive activity. We assumed three general domains of individual differences influencing regulatory decisions: intellectual factors, including epistemological beliefs, but also measures of the attractiveness of complex learning (Need for Cognition) and regulatory knowledge (Metacognitive Awareness); affective factors, including coping orientations and efficacy; and contingency response factors such as responsibility, volitional control behaviours, and procrastination patterns. In other words, we assumed that how doctoral students responded to the challenges of learning (metacognitive control) would reflect a greater constellation of influences than epistemology and regulatory knowledge alone.

The factor structure derived in that study gave some support to the proposition that metacognitive regulation may emerge from a broader frame of reference than the level of regulatory knowledge. The positive factor of Coping was an amalgam of elements of the predicted three domains of influence. It included recognition of the procedural demands of doctoral study along with a positive sense of efficacy, endorsement of constructive coping strategies, and a reliance on self-enhancement as the primary volitional goal. 
Interestingly, it was only the procedural aspect of epistemology that loaded on this factor: the notions of openness of knowledge and attractiveness of complex learning (Need for Cognition) had neutral loadings. If the strength of loading of constituent elements within a factor provides some indication of what is at the forefront of the candidate's concerns, then the factor indicates those who 'get' the task and are focusing on what is needed to manage it the processes of intellectual development, the management of affect, and the constructive volitional strategies, all buttressed by a strong positive sense of doctoral efficacy.

By contrast, both openness of knowledge and attractiveness of complex learning had negative loadings on the Naivety and Disengagement factors. Cartwright, Galupo, Tyree, and Jennings (2009) have demonstrated a significant positive association between a measure of post-formal reasoning and need for cognition in an undergraduate population. This suggests a relationship between the likelihood of Formal-2 reasoning as defined by Biggs and Collis (1989) and a willingness to expend the intellectual effort required to represent the 'doctoral problem' in sufficiently abstract terms (itself dependent on an acknowledgement of the openness of knowledge). In turn, this suggests that, in conjunction with the less sophisticated epistemology and lower need for cognition associated with both the Naivety and Disengagement factors, less constructive frames of reference are available for regulatory interventions. This may well explain both the lower levels of reported efficacy and the greater likelihood of using less task-centred volitional strategies and procrastinatory behaviours within the Naivety factor, whereas for those (overlapping) students who endorse the Disengagement factor, this limited metacognitive frame associates logically with an abrogation of personal responsibility for progressing candidature.

In summary, the three identified factors (combined with the associations between these factors and the cluster groupings) suggested to us the possibility that metacognitive responses to the complex, abstract, and difficult tasks associated with doctoral study involve a complex array of decisions about the learning process. Some of these are about basic regulatory activity. Others are about the nature of knowledge to be addressed, the procedural capacity to undertake this level of knowledge acquisition, and the management of the uncertainties associated with this. Affective management appears to us to be as central to explaining metacognitive decision making as does the quality of the underlying conception of the task. Affect enters the equation not only in the attractiveness of complex learning, as indicated by need for cognition, but also in the associated coping (proactive, reflective, preventative, support seeking), volitional (particularly the strength of self-enhancement), 


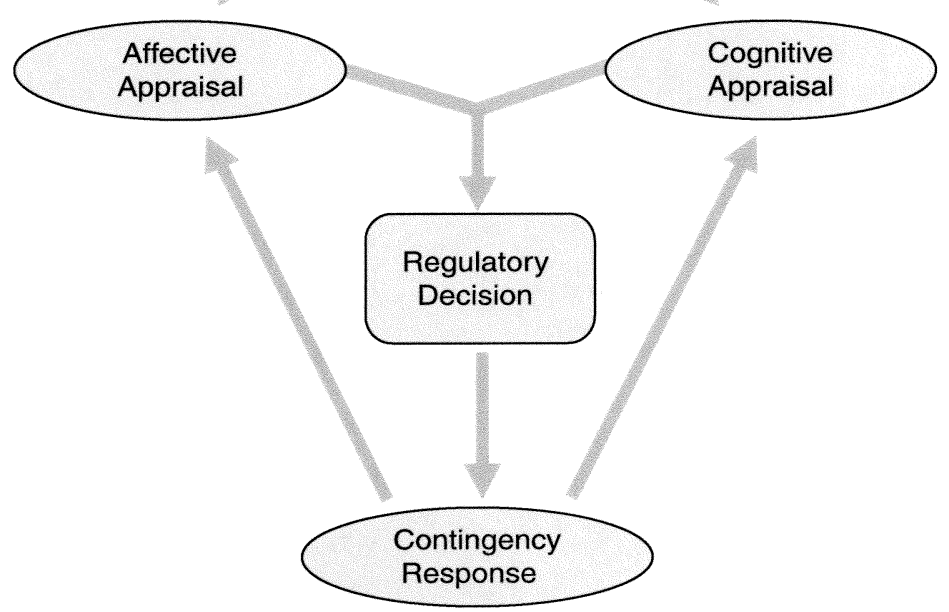

FIGURE 5.4. A model of epistemic metacognition.

and engagement (responsibility and procrastination) choices made as part of the learning process. Perhaps underpinning all of these choices is the sense of doctoral efficacy. For a task that involves the generation of a high-level contribution, metacognitive decision making appears to involve management of intellectual, affective, and contingency demands.

The substance of regulatory decision making emerges from a complex interplay of intellectual, affective, and contingency factors. We illustrate this interplay in Figure 5.4. Central in that model is what we term an 'Epistemic Metacognitive Framework' - a constellation of beliefs, attitudes, and understandings about learning that we construct through reflection on experience, and which we use for establishing criteria for engagement with the task at hand. These criteria inform both our intellectual (or cognitive) appraisal processes and our affective appraisal processes. Most critically, these two elements (cognitive and affective) interact to establish the particular form of the regulatory decision. The model also incorporates a feedback loop, by which evaluations of the regulatory decision are managed through contingency appraisal processes that re-inform both the cognitive and affective elements, and through these influence the epistemic representation of learning. Consider for example the strategy choices made in reviewing the literature. Writing a literature review 
requires that one immerse oneself in the literature and develop a position about that literature that indicates the breaking of new ground (see Holbrook, 2007; Holbrook, Bourke, Fairbairn \& Lovat, 2007). If the candidate is driven by a relatively closed sense of knowledge (a rejection or non-acknowledgement of uncertainty), and if the candidate finds complexity and abstract argument unattractive, the strategic choices will likely lead to a more limited conceptualisation of the scope of the task. In turn, the gap between expectation and conceptualisation will promote an affective appraisal that reinforces a lower sense of efficacy, non-task-centred volitional choices (e.g. use of negative incentives), and procrastination (as seen in the Naivety factor).

Such reasoning may, over time, crystallise as a dispositional framework through which subsequent regulatory choices are viewed. In this context, the metacognitive process implies the presence of a constructed set of beliefs about the task, about self, and about the relationship between these that sets the parameters for subsequent regulatory decisions. This we describe in Figure 5.4 as an epistemic metacognitive framework. It is a multi-dimensional framework, incorporating an internalised representation of the intellectual, affective, and contingency factors associated with 'usual' learning, and which, as demonstrated in the factor structure of the Cantwell et al. (2012) data, may lead to more or less constructive responses to task demands. As illustrated in Figure 5.4, this framework provides the individual's criteria for both affective and cognitive appraisals of the task at hand. Such appraisals are seen, through their interactions, as explaining the direction and quality of the regulatory outcomes.

\section{Conclusions}

Our aim in this chapter has been to examine the nature of the individual differences that influence the quality of engagement with doctoral study. We have proposed that how individuals engage is, at least in part, a function of an interaction between the perception of the task and the perception of the capacity to 'do' the task. In the case of the former, we gave emphasis to the notion of 'contribution', summarised in the expectation of a significant and original contribution to the field, and representing, cognitively, a Formal-2 level of functioning. In the case of the perceived capacity, we gave emphasis to the underlying dispositional basis of high-quality learning - those attributes that allow for functioning at the Formal-2 level. We identified three kinds of higher-order self-knowledge: knowledge of intellect, knowledge of affect, and knowledge of contingency. How these broad domains of self-knowledge interacted was seen as underlying individual differences in the quality of 
engagement with the doctoral task, differences representing a constructed epistemic metacognitive framework that can be expected to affect the quality of the learning during candidature.

There are significant limitations to the evidence we have outlined in this chapter. Although the evidence for the existence of epistemic metacognitive frameworks appears to us to be strong, further research is needed. The measures we report are representative of influences on metacognitive decision making among doctoral students, but are not exhaustive of all potential indicators. Moreover, there is a question of whether the constellations of beliefs identified represent stable dispositions or more specific time/task interactions. Given the complexity of the doctoral process, it may well be that the components of epistemic metacognitive beliefs change both with specific task requirements and with the developmental progression through the doctoral program. The predictive power of the constructs we report has not as yet been tested, although a larger-scale longitudinal study of this is currently being undertaken by the authors.

\section{References}

Arbuckle, J. (2008). Amos 17.0.o. Crawfordville, FL: Amos Development Corporation.

Basseches, M. A. (1984). Dialectical thinking and adult development. New York: Ablex.

Biggs, J., \& Collis, K. (1989). Towards a model of school-based curriculum development and assessment using the SOLO taxonomy. Australian Journal of Education, $33,151-163$.

Bourke, S., \& Holbrook, A. (2010). How examiners identify quality of research theses. Paper accepted in a symposium 'Exploring and managing uncertainty throughout the doctoral process', to be presented at the Australian Association for Educational Research Annual Conference, Melbourne, 28 November-2 December.

Bourke, S., Holbrook, A., Lovat, T., \& Farley, P. (2004). Attrition, completion and completion times of PhD candidates. Paper presented at the Annual Conference of the Australian Association for Research in Education, Melbourne, 28 November-2 December. Published at http://www.aare.edu.au/o4pap/bouo4849.pdf

Bromme, R, Pieschl, S., \& Stahl, E. (2010). Epistemological beliefs are standards for adaptive learning: A functional theory about epistemological beliefs and metacognition. Metacognition and Learning, 5, 7-26.

Cacioppo, J. T., Petty, R. E., \& Kao, C. F. (1984). The efficient assessment of Need for Cognition. Journal of Personality Assessment, 48, 306-307.

Cantwell, R. (2004). Positioning the bar: Outcomes associated with successful completion of an enabling course. Australian Journal of Adult Learning, 44, 354-389.

(2007). What have I got myself into? About learning and being at university. In J. Scevak \& R. Cantwell (Eds.), Stepping stones: A guide for mature-aged students at university (pp. 28-35). Melbourne: Australian Council for Educational Research. 
(2010). The nature of academic learning. In R. Cantwell \& J. Scevak (Eds.), An academic life: A handbook for new academics (pp. 25-34). Melbourne: Australian Council for Educational Research.

Cantwell, R., Archer, J., \& Bourke, S. (2001). A comparison of the academic experiences and achievement of university students entering by traditional and non-traditional means. Assessment and Evaluation in Higher Education, 26(3), 21-34.

Cantwell, R., Scevak, J., Bourke, S., \& Holbrook, A. (2012 in press). Identifying individual differences among doctoral candidates: A framework for understanding problematic candidature. International Journal of Educational Research. doi:10.1016/ j.ijer.2012.02.001

Cartwright, K., Galupo, M., Tyree, S., \& Jennings, J. (2009). Reliability and validity of the Complex Postformal Thought Questionnaire: Assessing adults' cognitive development. Journal of Adult Development, 16, 183-189.

Colebatch, H. K. (2002). Through a glass darkly: Policy development on higher degree completions in Australia. Journal of Higher Education Policy and Management, 24(1), 27-35.

Denicolo, P. (2003). Assessing the PhD: A constructive view of criteria. Quality Assurance in Education, 11, 84-91.

DEEWR (2010). Selected Higher Education Statistics. Downloaded from http://www. deewr.gov.au/HigherEducation/Publications/HEStatistics/Publications/Pages/ Students.aspx.

Greenglass, E., Schwartzer, R., Jacubiec, D., Fiksenbaum, L., \& Tauber, S. (1999). The Proactive Coping Inventory (PCI): A multidimensional research instrument. Paper presented at the 2oth International Conference of the Stress and Anxiety Research Society (STAR), Cracow, Poland, July 12-14. Available online at http://userpage. fu-berlin.de/ health/poland.htm/

Holbrook, A. (2007). Levels of success in the use of the literature in a doctorate. South African Journal of Higher Education, 21, 1020-1041.

Holbrook, A., \& Bourke, S. (2010). Modelling and validating an approach to maximise consistency in research thesis examination. Manuscript in preparation.

Holbrook, A., Bourke, S., Fairbairn, H., \& Lovat, T. (2007). Examiner comment on the literature review in $\mathrm{PhD}$ theses. Studies in Higher Education, 32, 337-356.

Holbrook, A., Bourke, S., Lovat, T., \& Dally, K. (2004). Investigating PhD thesis examination reports. International Journal of Educational Research, 52, 35-47.

Kleuver, R. C., \& Green, K. E. (1998). The Responsibility Scale: A research note on dissertation completion. Educational and Psychological Measurement, 58, 520-531.

Kramer, D. A. (1989). Development of an awareness of contradiction across the life span and the question of postformal operations. In M. L. Commons, J. D. Sinnott, F. A. Richards, \& C. Armon (Eds.). Adult development: Comparisons and applications of developmental models (pp. 133-159). New York: Praeger.

Mason, L., Boldrin, A., \& Ariasi, N. (2010). Epistemic metacognition in context: Evaluating and learning online information. Metacognition and Learning, 5, 67-90.

McCann, E. J., \& Garcia, T. (1999). Maintaining motivation and regulating emotion: Measuring individual differences in academic volitional strategies. Learning and Individual Differences, 11, 259-279.

Mezirow, J. (1991). Transformative dimensions of adult learning. San Francisco: JosseyBass. 
Muis, K., \& Franco, G. (2010). Epistemic profiles and metacognition: Support for the consistency hypothesis. Metacognition and Learning, 5, 27-45.

Muszynski, S. Y., \& Akamatsu, T. J. (1991). Delay in completion of doctoral dissertations in clinical psychology. Professional Psychology: Research and Practice, 22, 119-123.

Powell, S., \& Green, H. (2003). Research degree examining: Quality issues of principle and practice. Quality Assurance in Education, 11, 55-63.

Powell, S., \& McCauley, C. (2002). Research degree examining - common principles and divergent practices. Quality Assurance in Education, 10, 104-115.

PASW Statistics (2009). PASW 18.o. Chicago: SPSS Inc.

Richter, T., \& Schmidt, S. (2010). Epistemological beliefs and epistemic strategies in selfregulated learning. Metacognition and Learning, 5, 47-65.

Scevak, J., Budd, J., \& Cantwell, R. (2010) 'I never thought to ask the student what they think a PhD is.' Paper presented at the Annual Conference of the Australian Association for Research in Education. Melbourne, 29 November-3 December.

Scevak, J., Cantwell, C., Bourke, S., \& Reid, A. (2007). A metacognitive profile of doctoral students. Paper presented at the 12th Biennial Conference of the European Association for Research on Learning and Instruction, Budapest, Hungary, 28 August 28-1 September.

Schommer, M. A. (1993). Epistemological development and academic performance amongst secondary students. Journal of Educational Psychology, 85, 406-411.

Schraw, G., \& Denison, R. (1994). Assessing metacognitive awareness. Contemporary Educational Psychology, 19, 460-475.

ten Cate, O., Snell, L., Mann, K., \& Vermunt, J. (2004). Orienting teaching toward the learning process. Academic Medicine, 72, 219-228.

Tennant, M. (2000). Adult learning for self-development and change. In A. L. Wilson \& E. R. Hayes (Eds.), Handbook of adult and continuing education (pp. 87-100). New York: Wiley.

Tennant, M., \& Pogson, P. (1995). Learning and change in the adult years: A developmental perspective. San Francisco: Jossey Bass.

Veenman, M., Van Hout-Wolters, B., \& Afflerbach, P. (2006). Metacognition and learning: Conceptual and methodological considerations. Metacognition and Learning, $1,3-14$.

Vermunt, J. (1998). The regulation of constructive learning processes. British Journal of Educational Psychology, 68, 149-171.

Vermunt, J. D., \& Vermetten, Y. J. (2004). Patterns in student learning: Relationships between learning strategies, conceptions of learning, and learning orientation. Educational Psychology Review, 16, 359-384. 